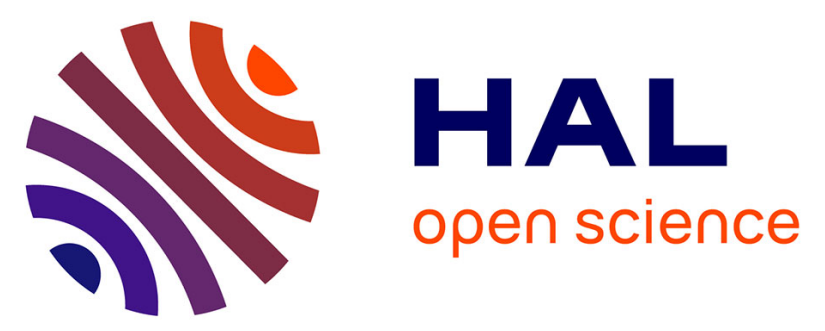

\title{
Cassini RADAR images at Hotei Arcus and western Xanadu, Titan: Evidence for geologically recent cryovolcanic activity
}

S. D. Wall, R. M. Lopes, E. R. Stofan, C. A. Wood, J. L. Radebaugh, S. M. Hörst, B. W. Stiles, R. M. Nelson, L. W. Kamp, M. A. Janssen, et al.

\section{To cite this version:}

S. D. Wall, R. M. Lopes, E. R. Stofan, C. A. Wood, J. L. Radebaugh, et al.. Cassini RADAR images at Hotei Arcus and western Xanadu, Titan: Evidence for geologically recent cryovolcanic activity. Geophysical Research Letters, 2009, 36 (4), pp.04203. 10.1029/2008GL036415 . hal-00405364

\section{HAL Id: hal-00405364 https://hal.science/hal-00405364}

Submitted on 16 Aug 2021

HAL is a multi-disciplinary open access archive for the deposit and dissemination of scientific research documents, whether they are published or not. The documents may come from teaching and research institutions in France or abroad, or from public or private research centers.
L'archive ouverte pluridisciplinaire HAL, est destinée au dépôt et à la diffusion de documents scientifiques de niveau recherche, publiés ou non, émanant des établissements d'enseignement et de recherche français ou étrangers, des laboratoires publics ou privés.

$$
\text { Copyright }
$$




\title{
Cassini RADAR images at Hotei Arcus and western Xanadu, Titan: Evidence for geologically recent cryovolcanic activity
}

\author{
S. D. Wall, ${ }^{1}$ R. M. Lopes, ${ }^{1}$ E. R. Stofan, ${ }^{2}$ C. A. Wood, ${ }^{3}$ J. L. Radebaugh,${ }^{4}$ S. M. Hörst,${ }^{5}$ \\ B. W. Stiles, ${ }^{1}$ R. M. Nelson, ${ }^{1}$ L. W. Kamp, ${ }^{1}$ M. A. Janssen, ${ }^{1}$ R. D. Lorenz, ${ }^{6}$ J. I. Lunine, ${ }^{5}$ \\ T. G. Farr, ${ }^{1}$ G. Mitri, ${ }^{1}$ P. Paillou, ${ }^{7}$ F. Paganelli, ${ }^{2}$ and K. L. Mitchell ${ }^{1}$
}

Received 21 October 2008; revised 5 January 2009; accepted 8 January 2009; published 24 February 2009.

[1] Images obtained by the Cassini Titan Radar Mapper (RADAR) reveal lobate, flowlike features in the Hotei Arcus region that embay and cover surrounding terrains and channels. We conclude that they are cryovolcanic lava flows younger than surrounding terrain, although we cannot reject the sedimentary alternative. Their appearance is grossly similar to another region in western Xanadu and unlike most of the other volcanic regions on Titan. Both regions correspond to those identified by Cassini's Visual and Infrared Mapping Spectrometer (VIMS) as having variable infrared brightness, strengthening the case that these are recent cryovolcanoes. Citation: Wall, S. D., et al. (2009), Cassini RADAR images at Hotei Arcus and western Xanadu, Titan: Evidence for geologically recent cryovolcanic activity, Geophys. Res. Lett., 36, L04203, doi:10.1029/2008GL036415.

\section{Introduction}

[2] The presence of cryovolcanism on Titan, particularly effusive features (cryoflows and domes), was proposed before the Cassini mission [Lorenz, 1993, 1996]. Models of Titan's interior suggest that cryovolcanism can occur on Titan [Tobie et al., 2006; Mitri and Showman, 2008; Mitri et al., 2008]. Several surface features interpreted as cryovolcanic in origin have been previously observed on Titan's surface by Cassini's $\mathrm{K}_{\mathrm{u}}$-band $(\lambda=2.17 \mathrm{~cm})$ Titan Radar Mapper (RADAR) [Elachi et al., 2005; Lopes et al., 2007] and by the spacecraft's Visible and Infrared Mapping Spectrometer (VIMS) [Sotin et al., 2005; Barnes et al., 2007].

[3] At this writing, RADAR's Synthetic Aperture (SAR) mode has imaged $>25 \%$ of Titan's surface [Elachi et al., 1991]. SAR resolution varies from $\sim 300 \mathrm{~m}$ to $1.5 \mathrm{~km}$ and is obtained in swaths from $150-400 \mathrm{~km}$ wide and up to $5000 \mathrm{~km}$ long [Elachi et al., 2005]. In addition to specific cryovolcanic features discussed below, these data show Titan's surface as geologically young, having a crater

\footnotetext{
${ }^{1}$ Jet Propulsion Laboratory, California Institute of Technology, Pasadena, California, USA.

${ }^{2}$ Proxemy Research, Bowie, Maryland, USA.

${ }^{3}$ Center for Educational Technologies, Wheeling Jesuit University, Wheeling, West Virginia, USA.

${ }^{4}$ Department of Geological Sciences, Brigham Young University, Provo, Utah, USA. USA.

${ }_{5}^{5}$ Lunar and Planetary Laboratory, University of Arizona, Tucson, Arizona,

${ }^{6}$ Space Department, Applied Physics Laboratory, Johns Hopkins University, Laurel, Maryland, USA.

${ }^{7}$ Observatoire Aquitain des Sciences de l'Univers, UMR5804, Université de Bordeaux, Floirac, France.
}

Copyright 2009 by the American Geophysical Union. 0094-8276/09/2008GL036415 retention age comparable with Earth or Venus ( $\sim 500 \mathrm{Myr})$ [Lorenz et al., 2007]).

[4] Most putative cryovolcanic features are located at mid to high northern latitudes [Elachi et al., 2005; Lopes et al., 2007]. They are characterized by lobate boundaries and relatively uniform radar properties, with flow features brighter than their surroundings. Cryovolcanic flows are quite limited in area compared to the more extensive dune fields [Radebaugh et al., 2008] or lakes [Hayes et al., 2008]. Particularly striking is Ganesa Macula (50N, 87 W [see Neish et al., 2006, 2008]), and various flows, some emanating from craters. A large radar-bright flow or flow field, Winia Fluctus $(45 \mathrm{~N}, 30 \mathrm{~W})$, is at least $90,000 \mathrm{~km}^{2}$ in area [Lopes et al., 2007].

[5] Titan flyby T41 (22 February 2008) acquired a SAR image of Hotei Arcus, a semi-circular albedo feature $\sim 650 \mathrm{~km}$ in arc-length centered at $26 \mathrm{~S} 79 \mathrm{~W}$. A second image was acquired May 12, 2008 on flyby T43 (Figures 1 and 2). The two images have different incidence (24 and 21 degrees, respectively) and azimuth angles (357 and 177 degrees). The Cassini Imaging Science Subsystem (ISS, near-IR) and the 5 -micron channel in VIMS see Hotei as one of the brightest features on Titan [Barnes et al., 2005]. A portion of Hotei also appears to have fluctuated in infrared brightness over the last three years [Nelson et al., 2008, 2009a, 2009b]. A second area in western Xanadu at 10S 140W, seen by VIMS and discussed by Nelson et al. [2009b] as "region 2", is also reported as variable. This region was imaged by RADAR on flyby T13, on Apr 30, 2006 (Figure 2d).

\section{Discussion and Interpretation}

[6] The T41 and T43 SAR images show Hotei (Figures $2 \mathrm{a}$ and $2 \mathrm{~b}$ ) as a complex region with several distinct units having unusual morphology. At the east end of the T41 swath, along the southern edge (bottom of Figure 2a), generally elongated bands of bright (rough) material intermix with darker (smoother) material. Flowing northward from dark regions between bright elongated mountain ranges are six major fluvial channels similar to many others documented by Lorenz et al. [2008] and believed to carry or to have carried liquid methane. Hotei's channels are among the most SAR-bright features seen to date anywhere on Titan.

[7] From the middle to the top of the T41 and T43 swaths are many light gray areas apparently overlaid on a darker substrate. These SAR-brighter units have lobate and welldefined boundaries and some large patches apparently consisting of overlapping units. We interpret these as multiple, coalescing cryovolcanic lava flows where the SAR-brighter 


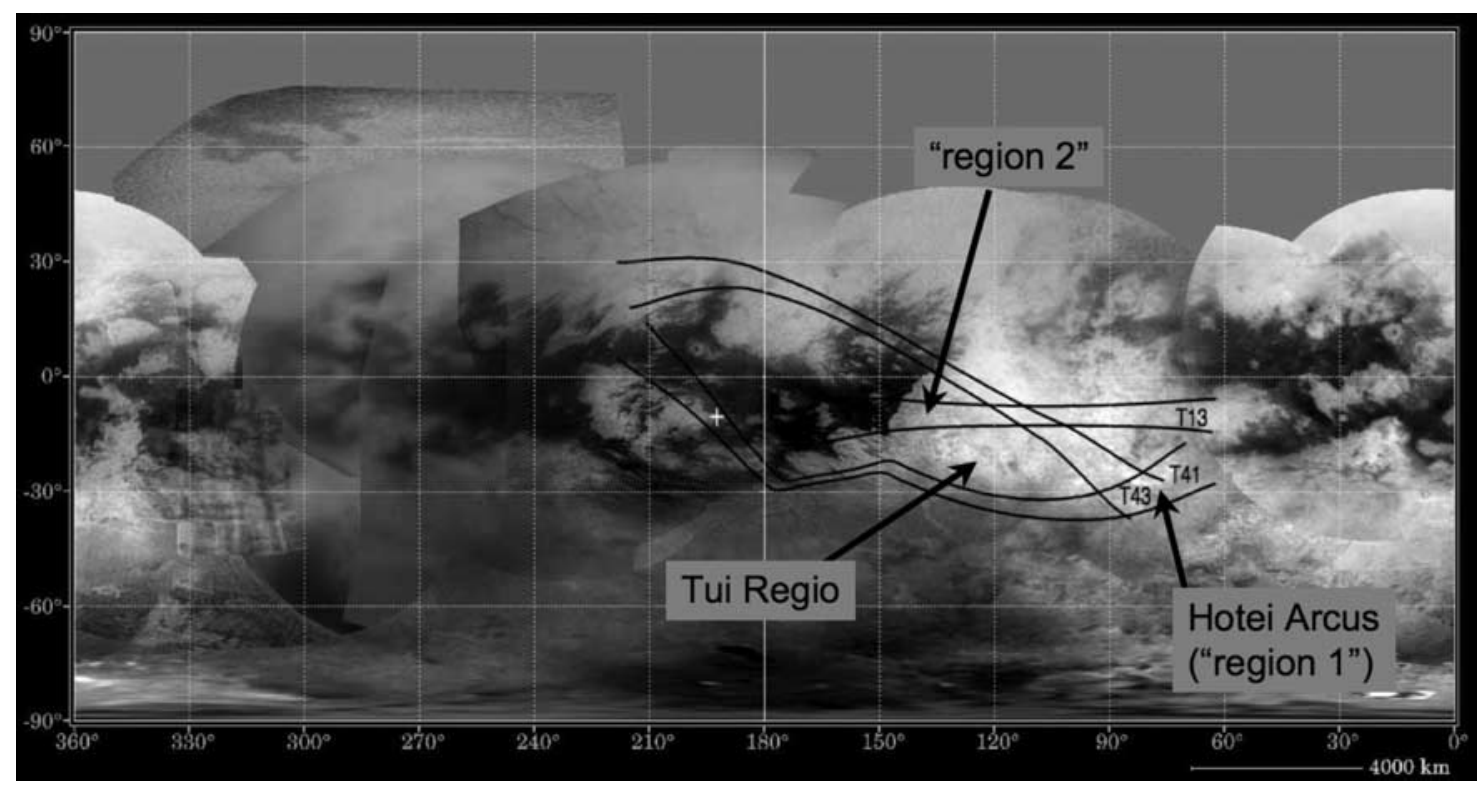

Figure 1. Location map on Titan globe, showing T13, T41 and T44 swaths and the two regions discussed in the text. Background is ISS image mosaic (JPL PIA08346).

unit has flowed over the darker substrate. Like cryolava flows previously observed on Titan, these are mostly uniform in radar backscatter. Both terrestrial and Venusian flows show similar lobate shape, texture, and brightness; and high radar backscatter has been associated with roughness and hence youth on terrestrial flows due to lack of erosion and infilling. Two examples are shown in Figure 3 [Evans et al., 1997; Campbell and Campbell, 1992; Campbell and Rogers, 1994; Bridges and McGill, 2002].

[8] The Hotei and western Xanadu flows are distinctly different from those previously identified by Lopes et al. [2007]. The previously identified flows could, in most cases, be traced to a source such as a caldera, were relatively isolated from other flows, and appeared to have followed topography and flowed in one direction. The flows at Hotei appear to have multiple sources and have flowed in a relatively flat area, resulting in coalescence of multiple flows.

[9] The distinct, uneroded appearance and the embayment and apparent superposition of surrounding areas are consistent with these flows being relatively young. The arcuate shape of the SAR-defined cryolava flows also suggests that only the southern edge of the basin floor is covered with recent cryolavas. These flow units have no superposed craters; however, the low density of impact craters on Titan [Lorenz et al., 2007] does not allow us to assign absolute ages to units. The channels coming from the south disappear where they reach the flow units - they appear to be covered by, hence older than, the flows. A calculation based on Huygens' site channels estimates that a minimum of $10^{3}$ methane rainstorms is required to cut them (S. Hörst, manuscript in preparation, 2009); a similar assumption at Hotei gives an upper limit of flow age of $10^{6}$ years, determined by the available energy to rehumidify the mid-latitude atmosphere with methane (see SI for details [Lorenz et al., 2005]).

[10] Comparison of the T41 and T43 SAR, taken about 11 weeks apart, reveals no obvious temporal changes at
Hotei, although the instrument performance in the T43 image is poor because the image is taken from the extreme end of the SAR swath. Relative brightening of features common to the two are to be expected due to the incidence and azimuth angle differences, and observed differences are typical of such brightening [Blom, 1988]. Where overlap occurs, and where noise effects do not dominate, feature shapes and unit boundaries match, and observed differences can be attributed to instrumental or geometric effects. We conclude that there is no evidence for morphologic surface changes at Hotei at the $\sim 1 \mathrm{~km}$ scale in this short time interval. Of course, SAR is insensitive to many other types of changes associated with volcanic activity, such as outgassing, that could occur on short timescales.

[11] The evidence provided here argues in favor of a cryovolcanic origin for the Hotei area. Alternate origins for the lobate deposits include sediments deposited by either fluvial processes or mass movement. A mass-movement origin is unlikely, given the apparent lack of topographic relief in the region as demonstrated by the intertwined appearance of the flows. Also, mass movement deposits typically leave behind a characteristic scarp or "crown" region ([Sharpe, 1968], see also discussion by Lopes et al. [2007]), which should be resolvable given the flow size and is not seen. A cryovolcanic origin for the channels can be ruled out from their dendritic nature and similarity to other Titan channels that clearly drain large areas not associated with volcanics [Lorenz et al., 2008]. Sedimentary deposits originating from the channels that flow into this region might create lobate flows. However, the deposits and the channels do not have the kind of spatial relationship that would be expected from a prograding or aggrading deltalike deposit, and the resemblance of the deposits to lava flow fields on Earth, Venus and other bodies, as mentioned above, is strong. However, we cannot completely rule out a sedimentary origin based on these data. 


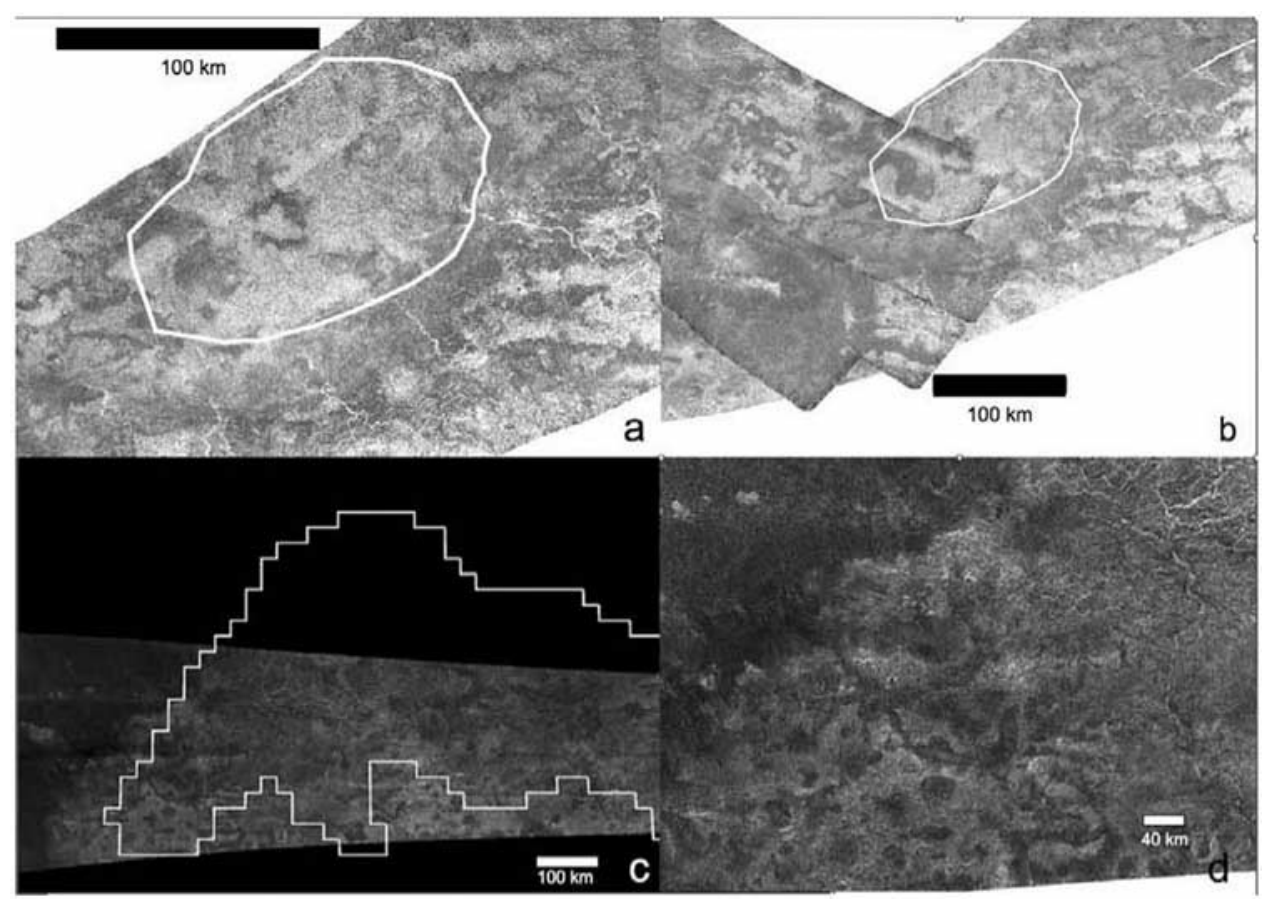

Figure 2. (a) T41 SAR image of Hotei Arcus, centered at 26S 79W, with outline of the corresponding VIMS image of "region 1" shown (see text). Incidence angle is $24 \mathrm{deg}$, with illumination from top left. (b) T43 SAR image of Hotei overlain on T41. Incidence angle is 14 deg, illumination from top right. (c) Western Xanadu from T13 SAR (centered at 10S, 140W), with outlines of VIMS "region 2". Incidence angle $=8$ degrees, illumination from top. (d) Enlargement of western side of Figure 2c. All images are oriented with north up. Digital images are available in the auxiliary material. ${ }^{1}$

[12] Independent of our interpretation of Hotei as cryovolcanic is the question of whether this interpretation supports the similarities to western Xanadu suggested by VIMS data. The outlines on Figures $2 \mathrm{a}$ and $2 \mathrm{~b}$ map the boundary of the 5-micron variable "region 1 " identified by VIMS, using reconstructed spacecraft position and attitude information for both instruments, and verified using a limb fit for VIMS data [Nelson et al., 2009a, 2009b]. The edges of the bright spot correspond well with the brightest of the SAR-observed flows. Hotei is bright to VIMS in reflected light at all wavelengths but especially at $5 \mu \mathrm{m}$, indicating that materials there are of different composition from their surroundings or are young [Barnes et al., 2005, 2006]. The outline of "region 2 " is similarly mapped in Figure $2 \mathrm{~d}$ onto the T13 SAR image, where the correspondence to interfingered, lobate light and dark features in the SAR image is also good. The flowlike features revealed in SAR images at Hotei and western Xanadu are superficially similar, but there are morphologic differences. In both areas the brighter features appear to overlie the darker, but these are more intertwined in Xanadu. Channels appear to be terminated by the bright unit in Hotei, but in western Xanadu they have a more complex relationship, and in some places channels cut through bright lobate units. Circular voids or pits are present in western Xanadu, with channels running through one, and brighter features reminiscent of ridges are seen on the bright unit, with no analog at Hotei. If the two regions are of similar origin, the western Xanadu flows may be older and more dissected and eroded. Based on the VIMS observations at Tui Regio [Barnes et al., 2006], we can speculate on the relationship of the possible flows on Hotei and Tui to the continent-sized Xanadu connecting them-perhaps the flows in western Xanadu are also related. Xanadu is centered near $15 \mathrm{~S}, 110 \mathrm{~W}$ and extends about $3000 \mathrm{~km}$ east to west and $1700 \mathrm{~km}$ north to south. Hotei is at its southeastern end, "region 2" at its western end, and Tui Regio at its southwestern end. Xanadu is bright in near-IR, at 5 microns, and at RADAR's $2-\mathrm{cm}$ wavelength, and is a strong anomaly in both scatterometry and radiometry maps [Wye et al., 2007; Janssen et al., 2008]. It has more impact craters than any other area of Titan imaged by SAR, is cut by major drainage networks, and appears to be being disaggregated by a process that replaces mountainous terrain with younger, darker material [Wood et al., 2007]. The existence of possible recent volcanism along two parts of Xanadu's southern border suggests that Xanadu is bounded by some type of tectonic margin that allowed cryomagma to escape to the surface.

\section{Conclusion}

[13] We have examined SAR images from two regions on Titan: Hotei Arcus and western Xanadu. Their bright features (a) exhibit generally similar morphology that is suggestive of volcanic flows; and (b) are in the same locations previously reported to be temporally variable in near-infrared VIMS data. Based on their general morphology and lack of relationship to fluvial channels, we interpret these features as young cryovolcanic flows. This interpretation is consistent with previous predictions and interior models, in particular with the Mitri et al. [2008] model that

\footnotetext{
${ }^{1}$ Auxiliary materials are available in the HTML. doi:10.1029/ 2008 GL036415.
} 


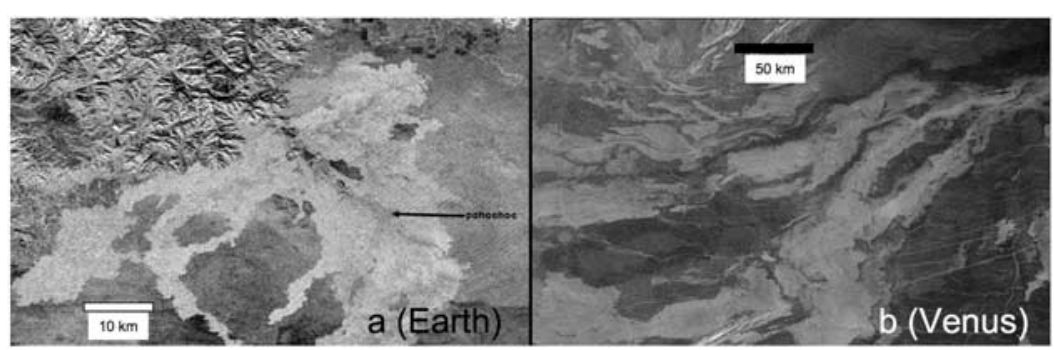

Figure 3. (a) Craters of the Moon, Idaho as imaged by the Shuttle Radar Topography Mission in 2000. Image is an average of C-band $(\lambda=5.5 \mathrm{~cm}) \mathrm{HH}$ and VV polarization swaths, with illumination from the south. Fine lineations running from upper right to lower left are radar image artifacts; (b) Kaiwan Fluctus flow field on Venus (Magellan Mission, S-band, $\lambda=12.6 \mathrm{~cm})$. Illumination is from left, incidence angle is 25 degrees.

requires tectonically-generated routes for magma to reach the surface.

[14] On Titan, the extrusion of liquid water from a subsurface ocean is aided by the presence of an antifreezing component, such as ammonia, to lower the melting point and density of the liquid [Stevenson, 1991; Kargel, 1992; Mitri et al., 2008]. Further, the observed features exhibit flow-like morphologies comparable with terrestrial basaltic lava flows (although the scales are typically different, e.g., Figure 3a), so the second component must produce a viscosity much higher than that of pure liquid water. Although the nature of this second component is not constrained by the SAR data, ammonia and/or methanol can provide silicate-like viscosity to water-rich flows under Titan gravity [Kargel et al., 1991]. Ammonia could also be the source of the nitrogen in Titan's atmosphere [Niemann et al., 2005] and the agent that lowers the melting point, density and mobility of liquid water [Lewis, 1971; Stevenson, 1982]. The Mitri et al. [2008] model of resurfacing by ammonia-water is consistent with the extent of the interpreted flow fields described here. Lorenz [1996] noted that expressing $10 \%$ of the heat released from a chondritic core as latent heat of ammonia hydrate (roughly the fraction of terrestrial heat flow expressed as the latent heat of eruptive basalt) corresponds to a resurfacing rate of $2 \mathrm{~mm} / \mathrm{yr}$, or some $\sim 100 \mathrm{~km}^{3} / \mathrm{yr}$, so recent or active cryovolcanism on Titan is not difficult from an energetics perspective.

[15] The flows at Hotei appear to be geologically young, less than $10^{6}$ years. Those in western Xanadu are of more uncertain age and probably older and more degraded. On shorter time scales, the SAR data cannot identify current activity except through morphological changes seen in repeat images, and on a time scale of tens of weeks no morphological changes are observed with confidence. The time baseline will be extended two terrestrial years in the Cassini Equinox Mission, though repeat coverage will remain sparse until a spacecraft is put in orbit around Titan.

[16] Acknowledgments. The authors acknowledge suggestions from members of the Cassini RADAR and VIMS Science Teams, and the designers and operators of Cassini spacecraft and radar. We are grateful to reviewers J. Kargel and J. Barnes for many helpful suggestions. A part of this work was carried out at JPL under contract with NASA.

\section{References}

Barnes, J. W., et al. (2005), A 5-micron-bright spot on Titan: Evidence for surface diversity, Science, 310, 92-95.

Barnes, J. W., et al. (2006), Cassini observations of flow-like features in western Tui Regio, Titan, Geophys. Res. Lett., 33, L16204, doi:10.1029/ 2006GL026843.
Barnes, J. W., et al. (2007), Near-infrared spectral mapping of Titan's mountains and channels, J. Geophys. Res., 112, E11006, doi:10.1029/ 2007JE002932.

Blom, R. G. (1988), Effects of variation in incidence angle and wavelength in radar images of volcanic and aeolian terranes, or now you see it, now you don't, Int. J. Remote Sens., 9, 945-965.

Bridges, N. T., and G. E. McGill (2002), Geologic map of the Kaiwan Fluctus quadrangle (V-44), Venus, U.S. Geol. Surv. Geol. Invest. Ser, I-2747.

Campbell, B. C., and D. B. Campbell (1992), Analysis of volcanic surface morphology on Venus from comparison of Arecibo, Magellan and terrestrial airborne radar data, J. Geophys. Res., 97, 16,293-16,314.

Campbell, B. A., and P. G. Rogers (1994), Bell Regio, Venus: Integration of remote sensing data and terrestrial analogs for geologic analysis, J. Geophys. Res., 99, 21,153-21,171.

Elachi, C., et al. (1991), Cassini Titan Radar Mapper, Proc. IEEE, 79, $867-$ 880

Elachi, C., et al. (2005), Cassini Radar views the surface of Titan, Science, 308, 970-974.

Evans, D. L., J. J. Plaut, and E. R. Stofan (1997), Overview of the Spaceborne Imaging Radar-C/X-Band synthetic-aperture radar (SIR-C/X-SAR) missions, Remote Sens. Environ., 59, 135-140.

Hayes, A., et al. (2008), Hydrocarbon lakes on Titan: Distribution and interaction with a porous regolith, Geophys. Res. Lett., 35, L09204, doi:10.1029/2008GL033409.

Janssen, M., et al. (2008), Titan's surface at $2.2-\mathrm{cm}$ wavelength imaged by the Cassini RADAR radiometer: Calibration and first results, Icarus, in press.

Kargel, J. S., et al. (1991), Rheological properties of ammonia-water liquids and crystal slurries: Planetological implications, Icarus, 89, 93-112.

Kargel, J. S. (1992), Ammonia-water volcanism on icy satellites: Phase relations at 1 atmosphere, Icarus, 100, 556-574.

Lewis, J. S. (1971), Satellites of the outer planets: Their physical and chemical nature, Icarus, 15, 174-185.

Lopes, R., et al. (2007), Cryovolcanic features on Titan's surface as revealed by the Cassini Titan Radar Mapper, Icarus, 186, 395-412.

Lorenz, R. D. (1993), The surface of Titan in the context of ESA's Huygens Probe, ESA J., 17, 275-292.

Lorenz, R. D. (1996), Pillow lava on Titan: Expectations and constraints on cryovolcanic processes, Planet. Space Sci., 44, 1021-1028.

Lorenz, R. D., C. A. Griffith, J. I. Lunine, C. P. McKay, and N. O. Rennò (2005), Convective plumes and the scarcity of Titan's clouds, Geophys. Res. Lett., 32, L01201, doi:10.1029/2004GL021415.

Lorenz, R. D., et al. (2007), Titan's young surface: Initial impact crater survey by Cassini RADAR and model comparison, Geophys. Res. Lett., 34, L07204, doi:10.1029/2006GL028971.

Lorenz, R. D., et al. (2008), Fluvial channels on Titan: Initial Cassini RADAR observations, Planet. Space Sci., 56, 1132-1144.

Mitri, G., and A. P. Showman (2008), Thermal convection in ice-I shells of Titan and Enceladus, Icarus, 193, 387-396.

Mitri, G., et al. (2008), Resurfacing of Titan by ammonia-water cryomagma, Icarus, 196, 216-224.

Neish, C. D., R. D. Lorenz, and D. P. O'Brien (2006), The potential for prebiotic chemistry in the possible cryovolcanic dome Ganesa Macula on Titan, Int. J. Astrobiol., 5, 57-65.

Neish, C. D., R. D. Lorenz, and R. L. Kirk (2008), Radar topography of domes on planetary surfaces, Icarus, 196, 552-564, doi:10.1016/ j.icarus.2008.03.013.

Nelson, R. M., et al. (2008), Saturn's Titan: Reports suggesting surface activity from Cassini VIMS and radar observations, Lunar Planet. Sci. Conf., 39th, 1862. 
Nelson, R. M., et al. (2009a), Saturn's Titan: Surface change, ammonia, and implications for atmospheric and tectonic activity, Icarus, in press.

Nelson, R. M., et al. (2009b), Photometric changes on Saturn's Titan: Evidence for active cryovolcanism, Geophys. Res. Lett., doi:10.1029/ 2008GL036206, in press.

Niemann, H. B., et al. (2005), Huygens Probe gas chromatograph mass spectrometer: The atmosphere and surface of Titan, Nature, 438, 779784.

Radebaugh, J., et al. (2008), Dunes on Titan observed by Cassini Radar, Icarus, 194, 690-703.

Sharpe, C. F. S. (1968), Landslides and Associated Phenomena, Cooper Square, New York.

Sotin, C., et al. (2005), Release of volatiles from a possible cryovolcano from near-infrared imaging of Titan, Nature, 435, 786-789.

Stevenson, D. (1991), Interior of Titan, in Proceedings of the Symposium on Titan, Eur. Space Agency Spec. Publ., ESA SP-338, 2933.

Stevenson, D. J. (1982), Volcanism and igneous processes in small icy satellites, Nature, 298, 142-144.

Tobie, G., J. Lunine, and C. Sotin (2006), Episodic outgassing as the origin of atmospheric methane on Titan, Nature, 440, 61-64.

Wood, C. A., et al. (2007), Volcanic calderas in the north polar region of Titan, Lunar Planet. Sci. Conf., 38th, 1454.
Wye, L. C., et al. (2007), Electrical properties of Titan's surface from Cassini RADAR scatterometer measurements, Icarus, 188, 367-385.

T. G. Farr, M. A. Janssen, L. W. Kamp, R. M. Lopes, K. L. Mitchell, G. Mitri, R. M. Nelson, B. W. Stiles, and S. D. Wall, Jet Propulsion Laboratory, California Institute of Technology, 4800 Oak Grove Drive, Pasadena, CA 91109, USA. (stephen.d.wall@jpl.nasa.gov)

S. M. Hörst and J. I. Lunine, Lunar and Planetary Laboratory, University of Arizona, 1629 E. University Boulevard, Tucson, AZ 85721, USA.

R. D. Lorenz, Space Department, Applied Physics Laboratory, Johns Hopkins University, 11100 Johns Hopkins Road, Laurel, MD 20723, USA.

F. Paganelli and E. R. Stofan, Proxemy Research, 12202 Raritan Lane, Bowie, MD 20715, USA.

P. Paillou, Observatoire Aquitain des Sciences de 1'Univers, UMR5804, Universite de Bordeaux, 2 rue de l'Observatoire, F-33270 Floirac CEDEX, France.

J. L. Radebaugh, Department of Geological Sciences, Brigham Young University, 150 East Bulldog Boulevard, Provo, UT 84602, USA.

C. A. Wood, Center for Educational Technologies, Wheeling Jesuit University, 316 Washington Avenue, Wheeling, WV 26003, USA. 